\title{
Pengaruh Kualitas Pelayanan, Fasilitas dan Lokasi terhadap Keputusan Menginap di Hotel Travellers Suites Medan
}

\author{
Anwar \\ Universitas Amir Hamzah \\ Anwar.nuar1963@gmail.com
}

\author{
Surya Hendra Putra \\ Politeknik Ganesha Medan \\ suryahendra@polgan.ac.id
}

\begin{abstract}
Abstrak
Penelitian ini dilatar belakangi oleh tingkat pertumbuhan hotel di Medan yang tinggi yang tidak diimbangi dengan peningkatan jumlah wisatawan yang seimbang. Hal ini tentu saja akan mempengaruhi jumlah pengunjung yang menginap di hotel.Hotel Travellers Suites Medan merupakan salah satu hotel yang terkena imbas dari ketidakseimbangan tersebut. Dapat dilihat dari terus turunnya jumlah pengunjung yang menginap di hotel ini sejak tahun 2015 s.d tahun 2019. Masalah dalam penelitian ini adalah " faktor - faktor apa yang mempengaruhi keputusan seseorang untuk menginap di Hotel Travellesr Suites Medan". Yang secara khusus difokuskan pada tiga variabel yaitu kualitas pelayanan, fasilitas dan lokasi. Tujuan dari penelitian ini adalah untuk dapat mempelajari pengaruh tiga variabel tersebut dalam mempengaruhi keputusan menginap di Hotel Travellers Suites Medan.Setelah melakukan kajian literatur dan penyusunan hipotesis, data yang dikumpulkan memalui kuesioner pada 80 tamu Hotel Travellesr Suites Medan yang diperoleh menggunakan teknik sampling sistematik. Kemudian dilakukan analisis data yang diperoleh dengan menggunakan analisis regresi berganda. Analisis ini mencakup: validitas dan reliabilitas, uji asumsi klasik, analisis regresi berganda, pengujian hipotesis melalui uji t dan $\mathrm{F}$, dan analisis koefisien deter minasi $\left(\mathrm{R}^{2}\right)$. Dari analisis tersebut diperoleh analisis regresi: $Y=\mathbf{0 , 3 0 8} \mathrm{X} \mathbf{1}+\mathbf{0 , 2 8 4} \mathrm{X2}$ + 0,303 X3Dimana variabel keputusan menginap (Y), kualitas pelayanan (X1), fasilitas (X2) dan Lokasi (X3) diuji menggunakan uji t menunjukkan bahwa ketiga variabel independen secara signifikan mempengaruhi keputusan menginap sebagai variabel dependen. Kemudian melalui uji F menunjukkan bahwa variabel kualitas pelayanan, fasilitas dan lokasi yang tepat untuk menguji variabel keputusan menginap. Angka Adjusted $R$ square sebesar 0,473 menunjukkan bahwa bahwa 47,3 persen variabel keputusan menginap dapat dijelaskan melalui ketiga variabel independen dalam persamaan regresi. Sedangkan sisanya 52,7 persen dijelaskan oleh variabel lain diluar ketiga variabel yang digunakan dalam penelitian ini.
\end{abstract}

Kata Kunci : Keputusan menginap, Kualitas pelayanan, Fasilitas, Lokasi 


\section{PENDAHULUAN}

\subsection{Latar Belakang Masalah}

Perkembangan persaingan bisnis di Indonesia adalah salah satu fenomena yang sangat menarik untuk kita simak, terlebih dengan adanya globalisasi dalam bidang ekonomi yang semakin membuka peluang pengusaha asing untuk turut berkompetisi dalam menjaring konsumen lokal.Industri perhotelan adalah industri jasa yang memadukan antara produk dan layanan. Desain bangunan, interior dan eksterior kamar hotel serta restoran,suasana yang tercipta di dalam kamar hotel, restoran serta makanan dan minuman yang dijual beserta keseluruhan fasilitas yang ada merupakan contoh produk yang dijual.

Perkembangan jumlah hotel di Medan yang sangat pesat, menimbulkan persaingan perhotelan di Medan menjadi sangat ketat. Menurut Ketua Persatuan Hotel dan Restoran Indonesia (PHRI), Heru Isnawan dalam Antara/FINROLL News mengatakan "Tingkat pertumbuhan hotel di Medan mencapai sekitar 20 persen setiap tahun, sedangkan kenaikan tingkat kunjungan wisatawan hanya mencapai sekitar 7-8 persen per tahun," Hotel Travellers Suites Medan merupakan salah satu hotel berbintang 4 yang ada di kota Medan yang berdiri sejak 20 tahun yang lalu. Hotel ini memiliki fasilitas kamar yang luas dan harga fantastic dan memiliki Restaurant dan Spa yang tradisional. Hotel ini memberikan fasilitas yang selalu membuat para tamu puas dengan kenyamanan yang diberikan hotel.

\subsection{Rumusan Masalah}

Dari masalah penelitian tersebut dapat dirumuskan pertanyaan-pertanyaan penelitian sebagai berikut :

1. Bagaimana pengaruh kualitas layanan terhadap keputusan menginap?

2. Bagaimana pengaruh fasilitas terhadap keputusan menginap?

3. Bagaimana pengaruh lokasi terhadap keputusan menginap?

\subsection{Tujuan Penelitian}

Berdasarkan pada latar belakang dan rumusan masalah, maka penelitian ini bertujuan:

1. Untuk menguji dan menganalisis pengaruh kualitas layanan terhadap keputusan menginap.

2. Untuk menguji dan menganalisis pengaruh fasilitas terhadap keputusan menginap.

3. Untuk menguji dan menganalisis pengaruh lokasi terhadap keputusan menginap

\section{LANDASAN TEORI}

Tjiptono (2006) menyatakan bahwa terdapat perbedaan fundamental antara pembelian barang dan pembelian jasa yaitu menyangkut proses konsumsi dan proses produksi. Pada barang terdapat, tahap pembelian dan konsumsi biasanya terpisah. Meskipun terdapat interaksi antara pemasar dan pelanggan selama tahap pembelian aktual, tahap pemakaian barang biasanya terlepas dari pengaruh langsung dari pemasar. Pelanggan bisa memilih kapan, di mana, dan bagaimana mereka menggunakan produk. Sedangkan dalam 
proses pembelian dan konsumsi jasa, sebagian besar jasa diproduksi dan dikonsumsi bersamaan. Konsekuensinya, perusahaan jasa berpeluang besar untuk secara aktif membantu pelanggan memaksimumkan nilai dari pengalaman konsumsinya.

Penyedia jasa bisa secara efektif mempengaruhi proses konsumsi dan evaluasi. Kotler dan Keller (2007) menyatakan bahwa kualitas pelayanan harus dimulai dari kebutuhan pelanggan dan berakhir pada persepsi pelanggan, dimana persepsi pelanggan terhadap kualitas pelayanan merupakan penilaian menyeluruh atas keunggulan suatu pelayanan.Aydin dan Ozer (2004) dalam Retansa (2009) menjelaskan pentingnya kualitas pelayanan untuk meningkatkan profitabilitas dan kesuksesan perusahaan.

Kualitas pelayanan berkaitan dengan keputusan pelanggan, kesempurnaan total atau superioritas pelayanan perusahaan.Menurut Tjiptono (2006) dengan fasilitas yang baik maka dapat membentuk persepsi di mata pelanggan. Di sejumlah tipe jasa, persepsi yang terbentuk dari interaksi antara pelanggan dengan fasilitas berpengaruh terhadap kualitas jasa di mata pelanggan.

Raharjani (2005) menyatakan bahwa apabila suatu perusahaan jasa mempunyai fasilitas yang memadai sehinggga dapat memudahkan konsumen dalam menggunakan jasanya dan membuat nyaman konsumen dalam menggunakan jasanya tersebut tersebut maka akan dapat mempengaruhi konsumen dalam melakukan pembelian jasa. Selain itu perusahaan yang memberikan suasana menyenangkan dengan desain fasilitas yang menarik akan mempengaruhi konsumen dalam melakukan pembelian.

\subsection{Kerangka Pemikiran}

Berdasarkan tinjauan landasan teori dan penelitian terdahulu, maka dapat disusun sebuah kerangka pemikiran teoritis seperti yang tersaji dalam gambar sebagai berikut :

\section{Kerangka Pemikiran Teoritis}

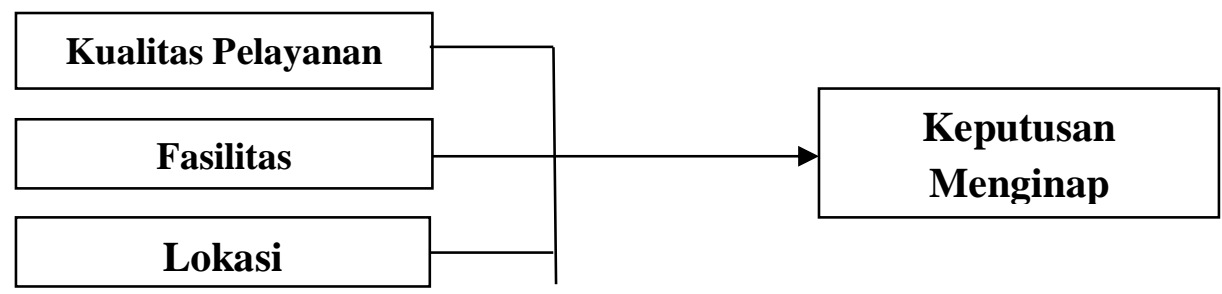

Sumber : dikembangkan untuk penelitian ini, 2019

\section{METODE PENELITIAN}

\subsection{Jenis dan Sumber Data Penelitian}


Data adalah semua keterangan yang dijadikan responden, maupun yang berasal dari dokumen, baik dalam bentuk statistik/dalam bentuk lainnya guna keperluan penelitian. Data diperoleh dengan nilai satu atau lebih variabel dalam sample atau populasi (kuncoro, 2001). Data dapat diklasifikasikan menjadi data kuantitatif dan data kualitatif.Sedakan menurut Indrianto dan Supomo (1999)

berdasarkan sumbernya, sumber data umumnya berasal dari:

a. Data primer merupakan sumber data yang diperoleh secara langsung dari sumbernya, dicatat untuk pertama kalinya dan berhubungan langsung dengan permasalahan yang diteliti. Data primer ini didapat melalui kuesioner (daftar pertanyaan) yang dibagikan dan diisi oleh 80 responden yang disusun berdasarkan variabel yang telah ditentukan dengan menyediakan jawaban alternatif.

b. Data primer dalam penelitian ini adalah data mengenai tanggapan responden terhadap variabel kualitas pelayanan, fasilitas dan lokasi serta data yang menunjukkan keputusan menginap yang dilakukan responden.Data SekunderData tingkat kunjungan, tingkat hunian kamar Hotel Travellers Suites Medan pada tahun 2015-2019, serta gambaran umum data sekunder adalah data yang diusahakan sendiri pengumpulannya oleh peneliti. Dalam penelitian ini data sekunder yang digunakan adalah referensi yang di peroleh melalui studi kepustakaan, untuk memperoleh informasi dari buku-buku referensi, dan sumber lainnya yang berhubungan dengan penelitian. Data sekunder ini mengacu pada objek penelitian yakni Hotel Travellers Suites Medan

\subsection{Penentuan Populasi dan Sampel}

\subsubsection{Populasi}

Menurut Dajan (1996) populasi merupakan keseluruhan unsur-unsur yang memiliki satu atau beberapa ciri atau karateristik yang sama. Berdasarkan ciri dan kharakteristik tersebut, populasi dapat dipahami sebagai kelompok individu atau proyek pengamatan yang minimal memiliki satu persamaan kharakteristik (Emory, 1995). Populasi dalam penelitian ini adalah pengunjung Hotel Traveller Suites Medan yang memakai jasa dan fasilitas dari pihak hotel tersebut.

\subsubsection{Sampel}

Sampel menurut Sugiyono (2001) merupakan bagian dari jumlah dan karakteristik yang dimiliki oleh populasi tersebut. Teknik pengambilan sampling yang digunakan adalah dengan non probability sampling yaitu teknik sampling yang tidak memberikan kesempatan sama bagi setiap unsur atau anggota populasi untuk dijadikan sampel. Sedangkan penentuan pengambilan jumlah responden (sampel) dilakukan melalui teknik accidental sampling atau sampling kebetulan, yaitu siapa saja yang secara kebetulan (accidental) bertemu dengan peneliti dapat digunakan sebagai sampel (Sugiyono, 2007). Pengambilan data dilakukan pada saat konsumen menginap di Hotel Travellers Suites Medan.jumlah sampel yang akan diteliti adalah sebesar 80 responden 


\section{HASIL DAN PEMBAHASAN}

Besarnya perubahan pada faktor dependen (Y) akibat perubahan pada faktor independen (X) secara parsial dapat dijelaskan melalui persamaan regresi yang diperoleh.

Coefficients $^{\mathrm{a}}$

\begin{tabular}{|c|c|c|c|c|c|c|c|c|}
\hline \multirow{2}{*}{\multicolumn{2}{|c|}{ Model }} & \multicolumn{2}{|c|}{$\begin{array}{l}\text { Unstandardized } \\
\text { Coefficients }\end{array}$} & \multirow{2}{*}{\begin{tabular}{|l} 
Standardi \\
Zed \\
Coefficie \\
Nts \\
Beta \\
\end{tabular}} & \multirow[b]{2}{*}{$\mathrm{t}$} & \multirow[b]{2}{*}{ Sig. } & \multicolumn{2}{|c|}{$\begin{array}{l}\text { Collinearity } \\
\text { Statistics }\end{array}$} \\
\hline & & $\mathrm{B}$ & Std. Error & & & & Tolerance & VIF \\
\hline \multirow[t]{4}{*}{1} & (Constant) & 3.745 & 1.303 & & 2.875 & .005 & & \\
\hline & $\begin{array}{l}\text { Kualitas_pela } \\
\text { yanan }\end{array}$ & 242 & .073 & .308 & 3.310 & .001 & .771 & 1.298 \\
\hline & Fasilitas & 211 & .071 & .284 & 2.967 & .004 & .729 & 1.371 \\
\hline & Lokasi & .298 & .094 & .303 & 3.173 & .002 & .732 & 1.366 \\
\hline
\end{tabular}

\section{Uji Koefisien Determinasi}

Koefisien determinasi digunakan untuk mengukur seberapa besar persentase perubahan atau variasi dari variabel dependen bisa dijelaskan oleh perubahan atau variasi dari variabel independen.Dengan mengetahui nilai koefisien determinasi dapat dijelaskan kebaikan dari model regresi dalam memprediksi variabel dependen. Semakin tinggi nilai koefisien determinasi akan semakin baik kemampuan variabel independen dalam menjelaskan perilaku variabel dependen. Hasil pengujian koefisien determinasi dapat dilihat dari nilai adjusted $R$ square pada analisis regresi berganda.

\section{Tabel Koefisien Determinasi}

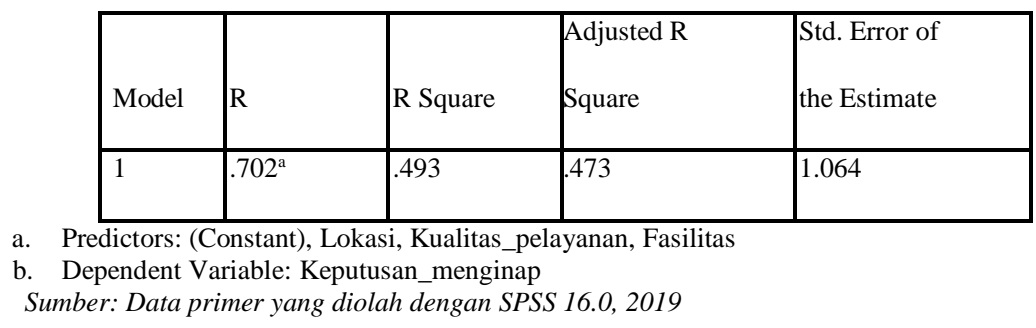

Berdasarkan Tabel koefisien determinasi memiliki adjusted $R$ square sebesar 0,473. Hal ini berarti 47,3\% keputusan menginap (Y) yang dapat dijelaskan oleh variabel-variabel independen yaitu variabel kualitas pelayanan, fasilitas, dan lokasi. Sedangkan sisanya $(100 \%-47,3 \%=52,7 \%)$ dijelaskan oleh variabel-variabel lain di luar model yang tidak dijelaskan dalam penelitian ini.

\subsection{Pengaruh Kualitas Pelayanan Terhadap Keputusan Menginap}

Variabel kualitas pelayanan berpengaruh positif dan memiliki pengeruh yang paling dominan terhadap keputusan menginap dengan koefisien regresi sebesar 0,308, Berdasarkan data responden 
dari keempat indikator pertanyaan yang diajukan, dapat dilihat bahwa responden lebih dominan memberi tanggapan setuju, diantaranya dalam indikator kecepatan dan ketepatan dalam memberikan pelayanan $52 \%$, keramahan dan kesopanan karyawan $37 \%$, pengertian atas kebutuhan para tamu $43 \%$ dan 50\% untuk respon terhadap keluhan dari para tamu. Sebagian besar responden menganggap baik kualitas pelayanan di Hotel Travellers Suites Medan

\subsection{Pengaruh Fasilitas Terhadap Keputusan menginap}

Variabel berikutnya adalah variabel Fasilitas berpengaruh positif dengan koefisien regresi sebesar 0,284. Berdasarkan data responden dari keempat indikator pertanyaan, dapat dilihat bahwa mayoritas responden memberi tanggapan setuju dari beberapa indikator pertanyaan diantaranya kamar yang bersih dan nyaman $49 \%$, penerangan dan pendingin udara yang baik $30 \%$, fasilitas keluarga yang yang nyaman $41 \%$, dan $47 \%$ untuk fasilitas parkir yang memadai. Hal ini membuktikan bahwa para tamu yang menginap di Hotel Travellers Suites Medan menganggap bahwa fasilitas yang disediakan pihak hotel baik.

\subsection{Pengaruh Lokasi Terhadap Keputusan Menginap}

Variabel berikutnya adalah variabel Lokasi berpengaruh positif dengan koefisien regresi sebesar 0,303.. Hal ini dapat dilihat berdasarkan data responden dari keempat indikator pertanyaan mayoritas responden memberi tanggapan setuju dari indikator pilihan kemudahan untuk dijangkau sebesar $62 \%$, kelancaran arus lalu lintas sebesar 53\%, lingkungan yang aman dan nyaman sebesar 41 $\%$ dan $52 \%$ untuk kedekatan fasilitas umum dengan lokasi hotel. Hal ini membuktikan bahwa para tamu yang menginap di Hotel Travellers Suites Medan menganggap lokasi hotel ini cukup strategis.

\section{KESIMPULAN DAN SARAN}

\subsection{Kesimpulan}

Berdasarkan hasil penelitian dan hasil analisis data, dapat ditarik beberapa kesimpulan sebagai berikut :

1. Pengaruh kualitas pelayanan terhadap keputusan menginap

Terdapat pengaruh secara positif dan signifikan dari variabel kualitas pelayanan terhadap variabel keputusan menginap. Hal ini didasarkan pada analisis kuantitatif, di mana hasil t hitung $(3,310)$ lebih besar dari t tabel $(1,9913)$. Indikator kecepatan dan ketepatan karyawan dalam memberikan pelayanan penting dalam mempengaruhi seseorang untuk menginap. Kecepatan dan ketepatan dalam memberikan pelayanan akan membeuat seorang tamu merasa senang dan puas terhadap pelayanan hotel tersebut.

2. Pengaruh fasilitas terhadap keputusan menginap

Terdapat pengaruh secara positif dan signifikan dari variabel fasilitas terhadap variabel keputusan menginap. Hal ini didasarkan pada analisis kuantitatif, di mana hasil t hitung $(2,967)$ lebih besar dari t tabel $(1,9913)$. Indikator kamar yang bersih dan nyaman penting dalam mempengaruhi seseorang untuk menginap. Pada dasarnya alasan seseorang menginap dihotel adalah untuk beristirahat, kamar yang bersih dan nyaman akan membuat seorang tamu merasa kerasan dan nyaman dalam beristirahat.

3. Pengaruh lokasi terhadap keputusan menginap. 
Terdapat pengaruh secara positif dan signifikan dari variabel lokasi terhadap variabel keputusan menginap. Hal ini didasarkan pada analisis kuantitatif, di mana hasil t hitung $(3,173)$ lebih besar dari $\mathrm{t}$ tabel $(1,9913)$. Indikator kemudahan dalam mengakses lokasi hotel penting dalam mempengaruhi seseorang untuk menginap. Lokasi yang mudah dijangkau akan memudahkan seseorang untuk melakukan mobilitas dari dan menuju ke hotel.

\subsection{Saran}

Beberapa saran yang dapat peneliti rekomendasikan kepada pihak manajemen Hotel Travellers Suites Medan.

1. Dari hasil pembahasan ditemukan bahwa kecepatan dan ketepatan dalam memberikan pelayanan merupakan faktor yang dominan dari kualitas pelayanan. Manajemen Hotel Travellers Suites Medan hendaknya makin memperhatikan kinerja dari para karyawannya. Setiap tamu yang akan melakukan pemesanan kamar hendaknya segera dilayani dan tidak dibiarkan terlalu lama menunggu. Setiap karyawan hendaknya diberikan pelatihan tentang seluk beluk perhotelan sehingga memiliki bekal pengetahuan yang cukup untuk dapat secara cepat memberikan pelayanan yang tepat sasaran.

2. Dari hasil pembahasan ditemukan kamar yang bersih dan nyaman merupakan faktor yang dominan dari fasilitas. Setiap room boy yang bekerja di Hotel Travellers Suites Medan harus memastikan bahwa kamar yang akan ditempati tamu harus benar - benar bersih dan tertata rapi . Jika terdapat perabot kamar yang rusak hendaknya segera diperbaiki agar tidak mengganggu kenyamanan para tamu pada saat menempati kamar tersebut.

3. Dari hasil pembahasan ditemukan keterjangkauan merupakan faktor yang dominan dari lokasi. Hal ini memberikan pertimbangan bagi pihak hotel agar memperhatikan kemudahan untuk menjangkau lokasi hotel apabila pada suatu saat ingin berpindah lokasi atau memperluas usahanya dengan mendirikan hotel baru.

\section{DAFTAR PUSTAKA}

Dwifebri, Anastasia, 2006, "Analisis Strategi Diferensi, Promosi Dan Kualitas Pelayanan Dalam Meningkatkan Minat Beli ( Studi Kasus Pada Patra Convention Hotel)”. Skripsi Tidak Dipublikasikan, Medan, Fakultas Ekonomi, Universitas Sumatera Utara

Engel, James F, 1994, "Perilaku Konsumen Jilid 1”, Jakarta: Binarupa Aksara.

Ghozali, Imam. 2003. "Aplikasi Analisis Multivariate dengan Program SPSS”. Badan Penerbit Universitas Diponegoro

Gutomo, Anjar, 2005, “ Analisis Faktor-Faktor Yang Mempengaruhi Keputusan Konsumen Dalam Menggunakan Jasa Warnet ( Studi Kasus Pada Warnet Grand Sylcomnet Di Tembalang )" Skripsi Tidak Dipublikasikan, Fakultas Ekonomi, Universitas Medan Area, medan.

Jurusan Manajemen Perhotelan, 2007, “Analisa Kualitas Layanan Sebagai Pengukur Loyalitas Pelanggan Hotel Majapahit Surabaya Dengan Pemasaran Relasional Sebagai Variabel Intervening”, http://www.petra.ac.id/ puslit/journals, Fakultas Ekonomi universitas Kristen 
Petra Kamus Besar Bahasa Indonesia, 1989 Departemen Pendidikan dan Kebudayaan, Jakarta Keputusan Menparpostel Nomor KM 37/PW. 340/MPRT-86. www.cari-pdf.com

Kotler, Philip, 2005, "Manajemen Pemasaran". Jilid I, Jakarta : Indeks --------------, 2005, "Manajemen Pemasaran”. Jilid II, Jakarta : Indeks.

Lukasyanti, Dewi, 2006, "Pengaruh Kualitas Pelayanan Terhadap Keputusan Menggunakan Jasa Pada Rumah Sakit Umum Daerah Kraton Kabupaten Pekalongan”. http://cari-pdf.com/, Fakultas Ekonomi Universitas Negeri Semarang

Lupiyoadi, Rambat \& A Hamdani, 2006. "Manajemen Pemasaran Jasa”. Jakarta :Salemba Empat

Lupiyohadi, Rambat, 2001 "Manajemen pemasaran jasa teori dan praktik”, Salemba Empat, Jakarta.

Retansa, Andika Reza, 2009, "Analisis Pengaruh Tingkat Pelayanan, Kualitas Pelayanan, dan Kepuasan Terhadap Loyalitas Nasabah Pada Bank BNI '46 Persero, Tbk. Cabang Semarang." Skripsi Tidak Dipublikasikan, Fakultas Ekonomi, Universitas Diponegoro, Semarang

Sulastiyono, Agus, 2006. "Manajemen Penyelenggaraan Hotel”. Bandung ; Alfabeta Suwiti, Ni Wayan dan Cecil Irwin Jr. Boham, 2008," Akomodasi Perhotelan”. Jilid III, PT Macanan Jaya Cemerlang, Klaten.

Suyanto, 2006, “ Analisis Pengaruh Persepsi Konsumen Tentang Kualitas Perbaikan, Pelayanan, dan Lokasi terhadap Keputusan Pembelian Jasa Bengkel ( Studi Kasus di Bengkel AHASS 1013 Yang Berada di Jalan Raya Kaligarang No 52 Semarang)." Skripsi Tidak Dipublikasikan, Fakultas Ekonomi, Universitas Diponegoro, Semarang

Swasta, Basu dan T Hani Handoko, 1987, "Manajemen Pemasaran”, Liberty, Yogyakarta.

Swasta, Basu, 2009,” Azas-Azas Marketing”, Yogyakrta : Liberty.

Tjiptono, Fandy, 2004,” Manajemen Jasa”, Andy Offset, Yogyakarta.

Zeithaml L, Valerie A; A. Parasuraman; Leonardo L. Berry, 1998, "Servqual a multiple-item scale for measuring consumer perception of service quality". Journal of Retailing, Vol. 64, no. 1, pp 12-37. 